\title{
National Language and Terminology Policies - A South African Perspective
}

Mariëtta Alberts, Department of Language Management and Lang Practice, University of the Free State, Bloemfontein, South Africa (malberts@lantic.net)

\begin{abstract}
Terminology plays a pivotal role in language development and the promotion of multilingualism. This article discusses the issue of multilingualism regarding terminology policies as seen from an African perspective. Special emphasis is given to the South African situation regarding language policies and consequential terminology policies in terms of subject-oriented terminography, translation-oriented terminography and linguistic community-oriented terminography.
\end{abstract}

Keywords: LANGUAGE POLICY, LINGUISTIC COMMUNITY-ORIENTED TERMINOGRAPHY, LINGUISTIC DIVERSITY, MULTILINGUALISM, SUBJECT-ORIENTED TERMINOGRAPHY, TERMINOLOGY DEVELOPMENT, TERMINOLOGY MANAGEMENT, TRANSLATION-ORIENTED TERMINOGRAPHY

Opsomming: Nasionale taal- en terminologiebeleid - 'n Suid-Afrikaanse perspektief. Terminologie speel 'n sleutelrol in taalontwikkeling en die bevordering van veeltaligheid. Hierdie artikel bespreek die kwessie van veeltaligheid ten opsigte van terminologiebeleid soos gesien vanuit 'n Afrikaperspektief. Spesiale klem word gelê op die Suid-Afrikaanse situasie rakende taalbeleid en die gevolglike terminologiebeleid in terme van vakgeörienteerde terminografie, vertaalgeörienteerde terminografie en taalgemeenskapgeörienteerde terminografie.

Sleutelwoorde: MEERTALIGHEID, TAALBELEID, TAALDIVERSITEIT, TAALGEMEENSKAPGEÖRIENTEERDE TERMINOGRAFIE, TERMINOLOGIEBESTUUR, TERMINOLOGIEONTWIKKELING, VAKGEÖRIENTEERDE TERMINOGRAFIE, VERTAALGEÖRIENTEERDE TERMINOGRAFIE

Unless people who speak African languages realise the importance of using them, the status of their languages will not improve.

Nomso Mgijima, The Sowetan, 23 February 2007

\section{Introduction}

Information is distributed and knowledge is acquired through terminology. The terminology of each subject field or domain is increasing with every new development or invention. The supplying of appropriate scientific, technical, educational and economic terms should be a national priority, especially in a multilingual dispensation. 
Should the terminology of the minority/marginalised/developing or standardised languages of the country be developed into functional terminologies, South Africans would be equipped with effective communication tools. Terminology development is also a vehicle appreciating the innovative skills of the language and subject-related communities within the country. In this sense, subject areas such as science, technology and economy can play a role in the development of languages as they have done with English, French, German, Chinese, Japanese, and Afrikaans to mention just a few. Languages can develop into functional languages through efforts of terminology development by language offices, private initiatives and publishers.

Terminology plays a pivotal role in language development and the promotion of multilingualism. The availability of (multilingual) polythematic terminology is an indicator of development since specialised communication has a central axle or hub in terminology. Standardised terminology contributes to the quality of translations, editing, interpreting services, dictionary compilation and specialised or subject related communication. Streamlined translation and interpreting services provide competitive advantages.

It is important to develop official languages into functional languages in all spheres of life. Information transfer, assimilation and retrieval should be through the first language or mother tongue. It is proven that information is best acquired (decoding process) and conveyed (encoding process) through the first language. Standardised terminology leads to exact communication and misinterpretation or misunderstanding are avoided.

Terminology, therefore, is a strategic resource and has an important role in a country regarding the functional development of languages and their users. Effective economic, scientific and technological transfer and assimilation of knowledge and skills amongst subject specialists and laypeople, and the communication skills of the citizens of a country are developed through the use of correct terminology. Although terminological and terminographical activities are not always cost-effective, they are of invaluable cultural, social, historical, functional, academic and scientific importance.

Terminology as a discipline, however, is governed by the language policy of the country. It is at the service of the language policy of the reigning government, e.g. monolingual, bilingual or multilingual. The South African situation could be taken as example:

- previous dispensation (i.e. prior to 1994): bilingual technical dictionaries were compiled (English/Afrikaans);

- present dispensation (i.e. after 1994): multilingual term lists are compiled in the eleven official languages of the country.

The concept "multilingualism" is very complex and the meaning or connotation attached to it in Europe may differ from that in Africa: "Africa has over 2000 languages and a rich and diverse linguistic heritage" (Chin 2009). In Africa, 
many different languages are spoken within the same political and geographical areas. The minimum number of languages spoken in African countries such as Nigeria, Ghana, Angola, Mozambique, Gabon, etc. is 40 for each country. Nigeria has in addition to the dominant languages such as English, Hausa, Ibo, Fulani and Yoruba more than 200 other languages spoken in the country. The Democratic Republic of Congo has more than 250 languages including the major languages, i.e. French, Swahili, Lingala, Kikongo and Ciluba. It is difficult, if not impossible, to be conversant in all these languages. Governments therefore need to recognise standard varieties spoken by majority groups as official languages. Languages foreign to Africa such as English, French, Portuguese, German, Spanish and Italian are not only spoken in almost $90 \%$ of the African continent, but these languages are also used as lingua franca between the indigenous African communities. Besides being used as lingua franca, these colonial languages are also used as official languages over and above the indigenous African languages. Some of the official indigenous languages are completely neglected and left to become extinct. Africans were to a certain extent made to believe that it is civilised to speak a "prestigious" European language. Reasons for this preference could be ascribed to aspects such as jealousies among Africans (i.e. not being prepared to accept another language to be elevated to official status); prestige or status of languages (standard vs. dialect); the colonial language is available, functional and developed; economic incentives; international status; and a wider audience for communication purposes. These attitudes regarding preference for colonial languages lead to the extinction of indigenous languages since children are deprived of learning and using their linguistic heritage (cf. Mojela 2007).

\section{Language policies of South Africa}

Wright (2007: 6) says about language planning and language policy:

Language planning and language policy express particular efforts at official social intervention and control in the sphere of language. Normally the direction and ambitions of language policy and planning embody an economic and social vision. In accord with this vision, certain aspects of current language practice in society are officially challenged or curbed, others are sustained and affirmed. In general, the aim of language policy is to move language practice in directions deemed desirable by those in power. Usually such attempts are applied through legislative measures ('policy') and allied material provision ('planning') to different social and political entities, such as geo-political regions, organised economic alliances, nations, provinces, industries, school systems, government departments, businesses and so forth.

In 1964 Valter Tauli (cf. Wright 2007: 6) defined language planning as "the activity of regulating and improving existing languages or creating new common regional, national or international languages. In 1992 Christopher Brumfit 
(cf. Wright 2007: 6) described language planning as "the attempt to control the use, status, and structure of a language through a language policy developed by a government or other authority". The Random House Dictionary of the English Language concurs, but adds some significant detail: Language planning is "the development of policies or programmes designed to direct or change language use, as through the establishment of an official language, the standardization or modernization of a language, or the development or alteration of a writing system".

According to Wright (2007: 7), a distinction can be made between natural and interventional language planning. Natural language planning actively supports the evolving language needs of a society as they emerge in response to other-than-linguistic pressures. Interventional language planning is prepared to challenge the impact on the language dispensation of current sociolinguistic forces. It would revitalise declining languages, preserve dialects, maintain languages that are under threat, modernise traditional languages for use in different domains, defend language rights, and nurture an ethically satisfying linguistic ecology. Existing language policies reflect different combinations of these two approaches.

The language policy of a country influences terminology development. Such a policy determines the number of languages to be developed as functional languages:

- Eastern Africa: One official language (Swahili), various national languages

- Namibia: Since 1992, only one official language (English), 16 national languages

- South Africa: Prior to 1994, two official languages (English and Afrikaans). Since 1994, eleven official languages (with special emphasis also on the development of South African Sign Language (SASL) and Khoe and San languages), many dialects.

Section 6 of Chapter 1 of the Constitution of the Republic of South Africa, 1996 (Act 108 of 1996) declared Sesotho sa Leboa (Northern Sotho), Setswana (Western Sotho or Tswana), Sesotho (South Sotho), Tshivenda (Venda), Xitsonga (Tsonga), Afrikaans, English, Siswati (Swati), IsiNdebele (South Ndebele), IsiXhosa (Xhosa) and IsiZulu (Zulu) as official languages of South Africa. According to the Constitution, "the state must take practical and positive measures to elevate the status and advance the use of these languages".

The South African language policy promotes the equitable use of the official languages. It also accommodates linguistic diversity. The language policy provides a regulatory framework to facilitate the effective implementation of the constitutional obligations concerning multilingualism. 
In accordance with the Constitution and the National Language Policy Framework (NLPF) and Implementation Plan (2003), the Government aims to promote South Africa's linguistic diversity. It proposes that optimal use be made of the country's linguistic resources by fostering respect for linguistic diversity and, by implication, for linguistic rights. Government aims to achieve this by means of an approach of functional multilingualism. This implies that the choice of a particular language in a particular situation is determined by the context in which it is used, i.e. the function, the audience and the message for which it is employed. The main criteria of functional multilingualism are language preference, use and proficiency.

Should the South African Government therefore need to communicate with the citizens of the country it is stipulated in the National Language Policy Framework (2003) that Government documents "shall be made available in all 11 official languages". In cases where this is not feasible, National Government Departments "shall publish documents simultaneously in at least six (6) official languages", i.e. Tshivenda, Xitsonga, Afrikaans, English, one from the Nguni group (i.e. IsiNdebele, Siswati, IsiXhosa, IsiZulu), and one from the Sotho group (i.e. Sesotho sa Leboa, Setswana, Sesotho). The three Sotho languages are mutually intelligible as are the four Nguni languages.

In occupations which are directly language-based, such as translation, interpreting, lexicography, terminography and copy-editing, and occupations which are directly language-dependent, such as in teaching, the media and tourism, the economic role of language is self-evident. Language is, however, also of central importance in the economic life of a country, i.e. as the major means of human communication, training (e.g. vocational training), effective management, trade negotiations, provision of services, job security and institutional loyalty and the job market (cf. Webb n.d.).

Considering the role of language in economic activity, it is a given that language can be either a barrier or a facilitator to economic activity. The role of language in economic performance is conditioned by the linguistic character of the community. In countries like Germany, France and the United Kingdom, which are largely dominated by one language, and where by far the majority of the population know that language, language may be less obviously an economic issue. In multilingual or highly multilingual countries, however, like practically all African states, language is exceptionally central, as is apparent from the situation in South Africa (cf. Webb n.d.).

Although the linguistic diversity and language services are costly, National Treasury, nonetheless, concluded after thorough investigation that it is possible to implement a multilingual language policy in South Africa. The expenditure is relatively small compared to overall departmental budgets. The result to aim for: enhanced communication between Government and the citizens of the country.

The distribution of the official languages in various provinces is an indication of the language variety in the country (PanSALB 2001a; see Table 1): 


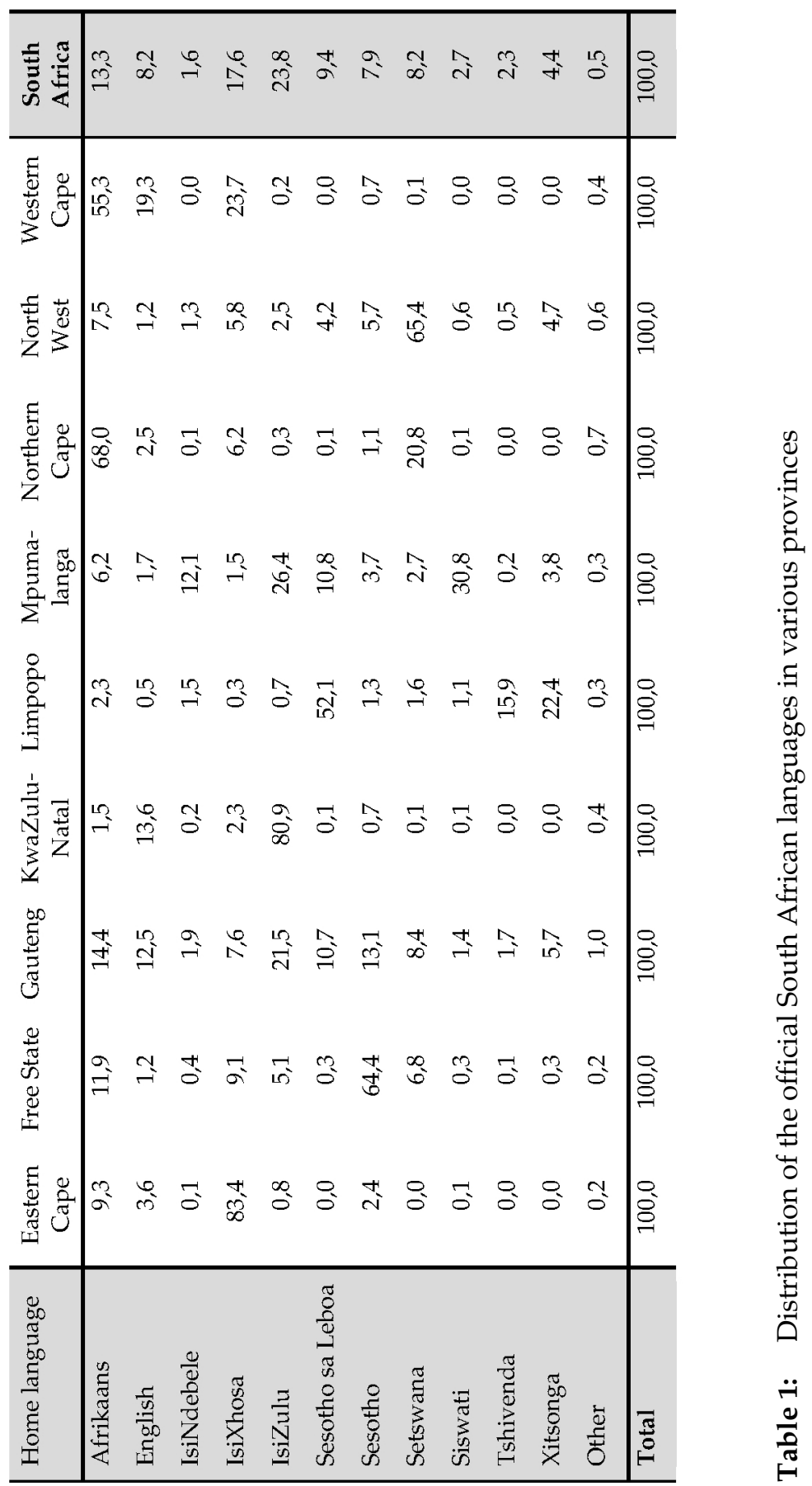


The Constitutional principle (limiting factor) governing the choice of languages to be used in official sectors of society is found in section 6(3)(a) of the Constitution. This section stipulates that usage, practicality, expense, regional circumstances and the balance of the needs and preferences of the population as a whole or in the province concerned (i.e. demographic, economic and attitudinal factors) will be taken into account in choosing the languages to be used in a specific sector (cf. Constitution 1996; NLPF 2003; PanSALB 2001b).

From a language planning point of view, the languages which people other than the educated elite understand and in which they are most competent, are as follows in descending order: IsiZulu, IsiXhosa, Afrikaans, and Setswana.

English is hardly used for neighbourhood communication in the Limpopo, Mpumalanga, North West, Free State, Northern Cape and Eastern Cape. Its functional use in neighbourhoods is limited to KwaZulu-Natal, Gauteng and the Western Cape. English is therefore useful as a lingua franca in only three provinces. IsiZulu is similarly used as a neighbourhood language in three provinces: KwaZulu-Natal, Gauteng and Mpumalanga. The use of Afrikaans as a neighbourhood language extends across five provinces: Northern Cape, Western Cape, Free State, Gauteng and Eastern Cape. As such it has a wider spread than any of the other languages (cf. PanSALB 2001a).

It is clear that there is no realistic opportunity for a single lingua franca across South Africa. A combination of Afrikaans and IsiZulu would take care of seven provinces. Limpopo and the North West have language needs for neighbourhood communication which are very specific to their respective provinces and which do not include English. IsiZulu ranks third after Afrikaans and English as a language of the educated elite. English is barely known amongst people with a less than Grade 10 qualification (cf. PanSALB 2001a).

One of the factors that ameliorates the asymmetrical treatment of languages in South Africa is the considerable multilingualism that is evident. This is reflected in the following results (PanSALB, 2001a; see Table 2):

\begin{tabular}{|l|l|r|}
\hline Afrikaans speakers & English & $50 \%$ \\
& African languages & $11 \%$ \\
\hline English speakers & Afrikaans & $54 \%$ \\
& African languages & $14 \%$ \\
\hline Sesotho speakers & Afrikaans & $24 \%$ \\
& English & $28 \%$ \\
& Other African languages & $30 \%$ \\
\hline Setswana speakers & Afrikaans & $24 \%$ \\
& English & $14 \%$ \\
& Other African languages & $20 \%$ \\
\hline Sesotho sa Leboa speakers & Afrikaans & $7 \%$ \\
& English & $19 \%$ \\
& Other African languages & $13 \%$ \\
\hline
\end{tabular}




\begin{tabular}{|l|l|r|}
\hline Siswati speakers & Afrikaans & $6 \%$ \\
& English & $27 \%$ \\
& Other African languages & $42 \%$ \\
\hline IsiNdebele speakers & Afrikaans & $10 \%$ \\
& English & $3 \%$ \\
& Other African languages & $19 \%$ \\
\hline IsiXhosa speakers & Afrikaans & $7 \%$ \\
& English & $24 \%$ \\
& Other African languages & $13 \%$ \\
\hline IsiZulu speakers & Afrikaans & $4 \%$ \\
& English & $32 \%$ \\
& Other African languages & $16 \%$ \\
\hline Tshivenda speakers & Afrikaans & $4 \%$ \\
& English & $0 \%$ \\
& Other African languages & $13 \%$ \\
\hline Xitsonga speakers & Afrikaans & $2 \%$ \\
& English & $24 \%$ \\
& Other African languages & $21 \%$ \\
\hline
\end{tabular}

Table 2: Levels of understanding of languages other than their own among home language groups

These results seem to illustrate the fallacy of assuming that a lingua franca exists in South Africa. Clearly South Africans need a more inclusive language policy than one based on the assumption that one language has sufficient reach to be an adequate medium of communication across the country (PanSALB 2001a).

Several varieties of informal languages exist around South Africa. These include the varieties known as Tsotsitaal/Flaaitaal and Isicamtho, which are patois developed from a blend of languages and serving as bridges for communication. They even differ from region to region in South Africa depending on the languages prevalent in a particular area (PanSALB 2001a).

South Africans are surprisingly generous in attempting to accommodate the practical challenges that arise in a country with eleven official languages. Substantial portions of citizens, however, have to accept less than adequate communication with their fellow South Africans and have to make difficult adjustments in formal situations and economic interaction.

Among better educated South Africans there is a clear indication of principled commitment to their own languages and the conviction that more should be done to develop minority languages. Among the less educated and rural communities there are a similar level of frustration based not on principles and ideals of linguistic equality, but on the reality that fluency in languages other than their own is critical for sheer economic survival (PanSALB 2001a). 


\section{Language development}

The term language development is defined in various ways. Haugen (1966) defines it as a process of changing a selected variety from an oral language to a written one. Cluver (1996: 1) reasons that language development is not a onetime process, but rather a continuing process referring to the planned modification of a selected variety to fulfil any new function that it did not fulfil previously.

Language development should be part of and contribute to the overall development of a community. One of the objectives of language development is to enhance the status of the language with its own speakers and with foreign speakers. The status of a language could be enhanced by proving to its users that it can be employed as a modern means of communication to function in domains in which languages of wider distribution function, i.e. education, the legal system, local administration, health care and modern agriculture (cf. Cluver 1996: 1-2; 6). Language development should refer to the whole language and include moves to develop the literary part of language as well (Cluver 1996: 7).

According to Cluver (1996: 2-3; 6), language development entails:

- language selection - the selection of a specific variety (e.g. dialect) for development,

- language codification - the development of a writing system, documentation of the existing vocabulary and grammar, development of spelling and orthography (for an unwritten language) or modernising existing spelling and orthographies and standardising the language,

- language elaboration - the expansion of the functions of the language so that it can operate beyond its traditional domains (home, family, community) as working language in the public domains (government offices, court of law, etc.),

- language spread - the development of the language as a language for teaching and learning (domain of education for primary school level, secondary school level and tertiary level), and a language of communication (e.g. media), and

- language modernisation - general terminology development in all spheres of the working environment, e.g. economy, science and technology (i.e. the expression of abstract concepts).

\section{Budin (2004: 6) alleges:}

Language development is much more than coining words and terms and thinking up spelling reforms. It is an ecological approach to language as a crucial element in human societies. It is more than language planning and standardization. It also includes multiple socio-linguistic factors. 
He further maintains that language development covers a mix of methods and approaches, including terminology and lexicography, terminology management, translation work and translation management, and increasingly corpusbased approaches (term extraction, corpus analysis for identifying neologisms coined in discourse communities, etc.).

Cluver (1996) claims that language welfare should reflect the welfare of the speech community and that language development should form an integral part of the development of any community by the community itself. He pleads for the first objective for language development in South Africa to be the production of a standard grammar, a standard general dictionary and technical terminologies for each of the official languages.

The practical problems of accommodating eleven official languages are such that current budgets cannot provide for adequate expenditure on language development, multilingual training and the creation of translation and interpretation services. There is a danger in a situation in which resources will always be limited that the challenges of language development will always be deferred. Government and decision-makers in the public and private sectors, however, know that one of their major obligations is to be understood by the citizens of the country. If less than half of the population is reached because of communication problems, there should be enough reason for a greater sense of urgency in respect of language development and multilingualism.

Currently various governmental and private initiatives are undertaken, aimed at promoting multilingualism by the redressing of past linguistic imbalances, developing the previously marginalised languages, and supplying multilingual polythematic terminologies.

\section{Brief historical overview of South African terminology practice}

The history of African language terminology in South Africa starts with structures similar to the erstwhile Language Boards that begun in 1928 with the formation of language committees (cf. Mayevu 1996: 30). These have been changing over the decades both in formation and focus (cf. Mtintsilana and Morris 1988).

Since 1948 the construction of the Language Boards has taken a fundamentally political outlook both in its composition, function and relation. These Boards were linked to 'independent homelands' and similar political formations. Their political role was to present a picture of separate development, primarily the homeland structures. Some of these Boards were actually accountable to the Chief Ministers and their Cabinets, some were accountable to the Department of Education and Training and some to both structures. These Boards were mainly funded by the homeland governments and had representatives of those governments as members (cf. Mtintsilana and Morris 1988). There were Language Boards for every African language, though some would be duplicated for political purposes as in the case of Transkei and Ciskei and 
Bophuthatswana (cf. Ntshangase 1996).

Officially the South African terminology practice started as early as 1950. Before then many terminology lists or technical dictionaries were compiled by individuals. The early stages of the official terminology practice were adhering to the then bilingual policy of the country.

Translators of the erstwhile Language Bureau of the Department of Culture (later Department of National Education), started documenting English and Afrikaans terms on index cards. Later a Terminology Division developed within the Language Bureau. Terminologists were appointed to excerpt terms from documents and to systematise and standardise the terminology of various subject fields. A variety of bilingual term lists and technical dictionaries were compiled and published.

Other language bureaus situated at government departments followed soon (e.g. the South African Defence Force (SADF), South African Railways and Harbours (SAR\&H), Department of Education, etc.). Soon thereafter several language bureaus at institutions such as the Suid-Afrikaanse Akademie vir Wetenskap en Kuns (SAAWK) (South African Academy for Science and the Arts), South African Iron and Steel Corporation (Iscor), Municipalities, South African Bureau of Standards (SABS), South African Broadcasting Corporation $(\mathrm{SABC})$, etc. that employed translators also had a few terminologists to excerpt the terminology of the relevant institution. They all started to compile bilingual terminology lists in order to standardise the terminology usage within these organisations. A Coordinating Terminology Board (COTERM) was formed in 1971 to coordinate the terminology endeavours of the various offices and to avoid duplication. The members of COTERM also started with initiatives to computerise the terminologies of the various organisations.

In 1976 the Terminology Division of the Department of National Education amalgamated with the Vaktaalburo (Terminology Bureau) of the SAAWK to form a new Terminology Bureau under the auspices of the Department. This Bureau was later named the National Terminology Services (NTS) of the Department of Arts, Culture, Science and Technology (DACST) and the office became the official national terminology office to document and disseminate terminology. This office took over the duties of COTERM.

In April 1998 the NTS and the State Language Services of DACST amalgamated to form the National Language Service (NLS). The NTS became the Terminology Coordination Section (TCS) of the NLS under the Department of Arts and Culture (DAC).

Although the TCS and its predecessors in the past primarily compiled bilingual, bi-directional technical dictionaries, it was soon realised that there was a pressing need for terminology in the various African languages. The TCS therefore started with research into word forming principles in the indigenous languages. It was decided to start compiling multilingual technical dictionaries in all national South African languages with the addition of extended information such as definitions and explanations. 
In 1994 South Africa obtained a multilingual policy and since then terminology projects are undertaken in the eleven official languages. African language terminologists, who are all first-language speakers of the various official languages, were employed since 1995 to document African language terminology on a variety of subject fields.

The TCS of the NLS provides a base of knowledge for all language groups on national, provincial and local government level and for all other spheres of technical and scientific communication. The office serves the whole community. This incorporates all levels of communication in all registers in which terminology of the official languages is needed - from grass-roots level to the higher echelons of science and technology.

The TCS of the NLS operates in close collaboration with external official and private multilingual projects, and with the Pan South African Language Board (PanSALB).

\section{Establishment of the Pan South African Language Board (PanSALB)}

The Pan South African Language Board (PanSALB) was established in 1996 to give effect to the letter and spirit of Section 6 of the Constitution of the Republic of South Africa. PanSALB is a constitutional body instituted in terms of the PanSALB Act (Act No 59 of 1995 as amended in 1999).

The Board was established to promote multilingualism and develop the official South African languages, including the South African Sign Language (SASL) and the Khoe and San languages.

PanSALB created advisory structures to assist it in achieving its mandate, namely to promote multilingualism, to develop languages, and to protect language rights.

PanSALB structures consist of

- nine Provincial Language Committees (PLCs) to assist the provinces with language policy formulation and implementation.

- thirteen National Language Bodies (NLBs) to take care of standardisation (e.g. spelling and orthography rules), terminology development, dictionary needs (general and specific), literature and media, research, and education.

- eleven National Lexicography Units (NLUs) to compile comprehensive monolingual and other types of dictionaries (i.e. bilingual translation dictionaries, etymological dictionaries, technical dictionaries, etc.).

Members of the PanSALB structures have a major communicative role to play in terms of information flow in all three directions. They should also monitor PanSALB's strategic objectives, implementation plan and the effectiveness thereof. 
The PLCs are provincial structures, each taking care of the languages of a specific Province and assist with the language policies of these provinces. The PLCs keep in contact with the NLBs and NLUs in order to make them aware of all the language needs that impact negatively or positively in terms of language policy, language practice, language implementation, and the promotion of multilingualism in a province.

The NLUs and NLBs are national structures. The language-specific NLB and NLU take care of the particular language or language group, the official language (where applicable) of the majority of the speakers of the language residing in the geolinguistic area, developmental issues regarding the language, and promotion and preservation of the language.

The NLUs were established as Section 21 Companies. Although they receive funding from PanSALB, they are autonomous. They are managed by Editors-in-Chief and function under the auspices of Boards of Directors. Their main aim is to compile comprehensive monolingual explanatory dictionaries to preserve and document the respective official languages. They may, according to needs, also compile bilingual and other types of dictionaries.

PanSALB's NLBs function according to technical committees (TCs) to develop standards, spelling and orthography rules, conduct research, verify and authenticate terminologies, and assist with the standardisation of terms, determine dictionary needs (for general and special purposes), facilitate production and promotion of literature and media, develop dialects, facilitate research studies, develop all bands of education, and facilitate the development and promotion of the SASL and the Khoe and San languages.

The TCs concerned with Terminology Development obtain terminology lists from the Terminology Coordination Section (TCS), the National Language Service (NLS), the Department of Arts and Culture (DAC), and other institutions or individuals who compile technical dictionaries or term lists. Their members could form part of the working groups who are busy compiling ongoing terminology projects. They could assist with research on problematic terms, term creation or word-forming principles relevant to the language concerned. They also give feedback to the parties concerned.

Once a terminology project is finalised the project is submitted to the relevant Technical Committee (TC): Terminology Development of the relevant NLB to verify and authenticate terms, assist with the standardisation and stabilisation of terms, popularise terms, advise compilers of technical dictionaries or term lists (i.e. private or institutionalised efforts), advise terminologists and terminology offices, and co-operate, collaborate and communicate with stakeholders.

The TC: Terminology Development should not only give feedback regarding term creation to the compilers of the terminology project, but also to the NLB concerned. They should furthermore give feedback to various institutions busying themselves with term creation regarding specific language developmental needs, requirements of the specific language and subject-oriented 
needs. These institutions should on the other hand, change their databases according to the discussions held with NLB members on, for instance, problematic terms. TC members could give input regarding term creation, spelling and orthography, word-forming principles, principles regarding neologisms, borrowing, transliteration, total embedding, etc.

The TC: Terminology Development of the NLB should present the term list to the NLB concerned to give its stamp of approval concerning the terminology project before the term list or dictionary could be disseminated to endusers (e.g. subject specialists, language practitioners, NLUs, and language users in general).

PanSALB drafted guidelines to assist each technical committee with the various tasks to be handled.

\section{Terminology policy and official terminology management in South Africa}

The need for unambiguous communication in theoretical and applied fields of human activity is constantly increasing. Unfortunately people use terminology without realising what it entails. It is the process of excerption, documentation, standardisation, publication and dissemination of terms. This is a time-consuming and labour-intensive process where specialised skills, commitment and devotion are needed.

A terminologist aims to provide unambiguous terms for well-defined concepts. In order to achieve this aim, it is necessary to determine the precise meanings of terms to enable users to comprehend and use them in a universally accepted manner.

Since the beginning of terminology development in South Africa, the source language (SL) for terminology documentation is usually English. The Afrikaans terminologies for various subject areas and domains were officially documented since 1950. Afrikaans terminologists and subject specialists therefore created terms for almost all subject areas and domains. This, however, is not the case for the other nine official South African languages. Owing to the great backlog concerning the development of these terminologies, various methodologies are being used to harvest terminology, i.e. subject-oriented terminography, translation-oriented terminography, and linguistic communityoriented terminography.

\subsection{Subject-oriented terminography}

The official South African terminology office, the Terminology Coordination Section (TCS) usually starts from a specific source language (SL), namely English, and translation equivalents have to be supplied in the other ten official South African languages. The national terminology office uses various methods 
but usually works according to the subject-oriented methodology for terminology harvesting.

The terminologists consult linguists and subject specialists when supplying or coining translation equivalents for SL terms. The National Terminology Services (NTS) used to work in close collaboration with the old Language Boards and at present the terminologists of the National Language Service (NLS) consult the National Language Bodies (NLBs) established by PanSALB.

The terminologies of all official languages should be developed to enhance the multilingual heritage of the country and to develop the languages into functional languages in all subject areas and domains. Unfortunately there are very few trained terminologists with even less terminology posts available.

The national terminology office, the Terminology Coordination Section (TCS), manages terminology as follows:

- The terminographers excerpt terminology in the SL which is usually (but not necessarily) English.

- The terms are then supplied with definitions, example sentences and relevant information in the SL.

- These terms and relevant information are discussed with subject specialists to confirm the contents.

- After the SL terms and relevant information have been finalised, the information is converted/translated into the target languages (TLs), e.g. Afrikaans and the nine official African languages.

- The information in the target languages is also discussed with collaborators and subject specialists before finalisation of the dictionary.

Language-specific collaborators, situated in the various provinces, were trained by senior TCS staff members on the basic principles and practice of terminology work. The idea is that these collaborators (mostly linguists or language practitioners) form the core group to assist the language-specific terminologists. When the terminologists for instance compile a Mathematics term list, the core group of collaborators would get subject specialists working in the field (e.g. teachers or lecturers in Mathematics) who are first-language speakers of the relevant language to assist them with the discussion of the terms and related information. The terminologist would then return to the office and change the database according to the suggestions made by the collaborators and subject specialists.

After the finalisation of a specific terminology list, the relevant NLB is requested by the TCS to verify and authenticate the terminology. After verification and authentication, the relevant terminologist changes the database according to the suggestions made by the language-specific NLB members. 
After the database has been finalised (e.g. all eleven official languages have been taken care of), the relevant terminology list can be published and disseminated to target users (cf. Diagram 1).

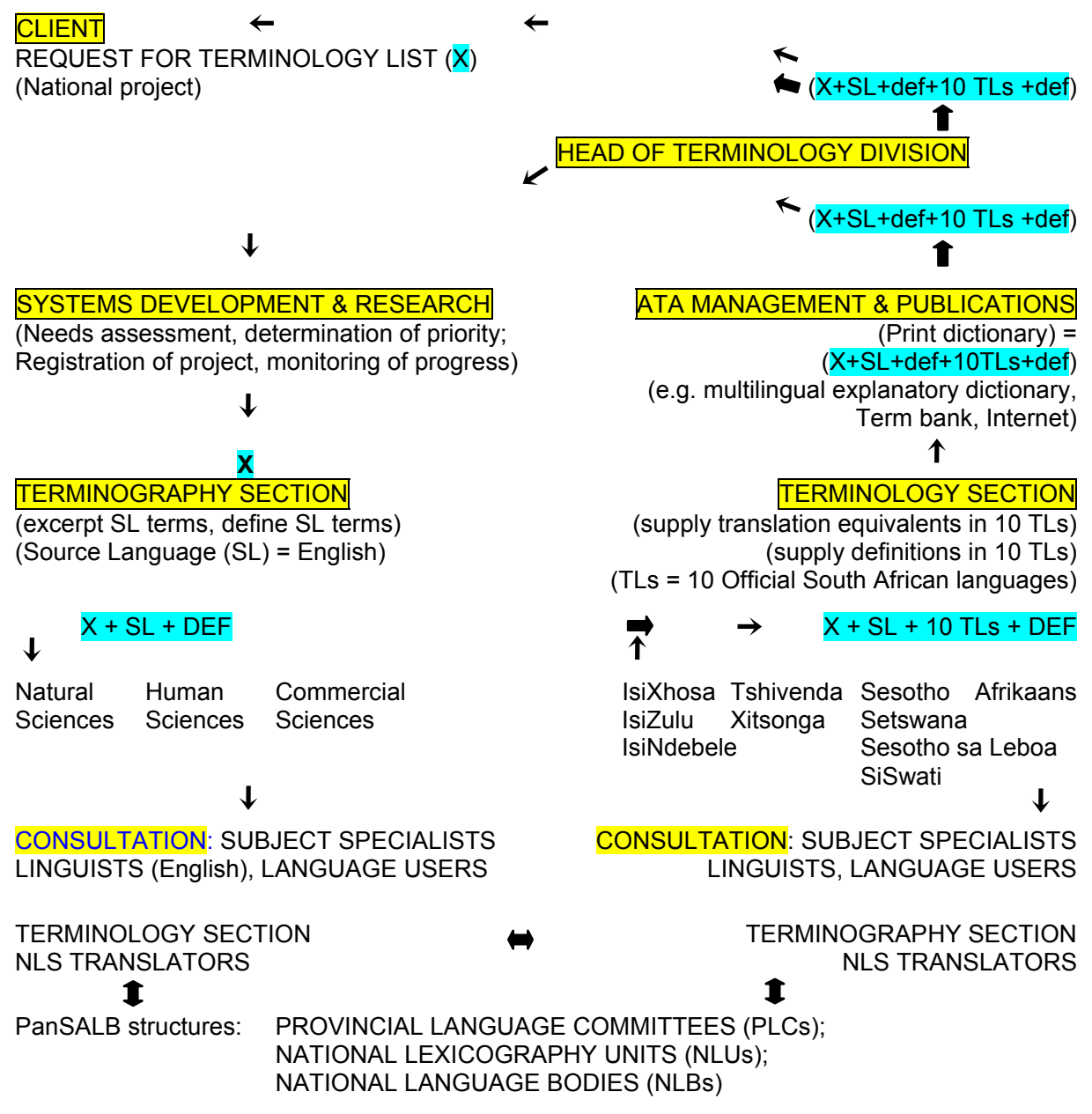

Diagram 1: Terminology flow diagram

\subsection{Translation-oriented terminography}

The National Language Service (NLS) also employs translators and therefore also takes part in translation-oriented terminography (TOT). Terms in the source language (SL) text and term equivalents in the target language (TL) translations are aligned and harvested (cf. Diagram 2). These terms and related information are then submitted to the Terminology Coordination Section (TCS) 
to be documented and processed in the manner described above and illustrated in Diagram 1.
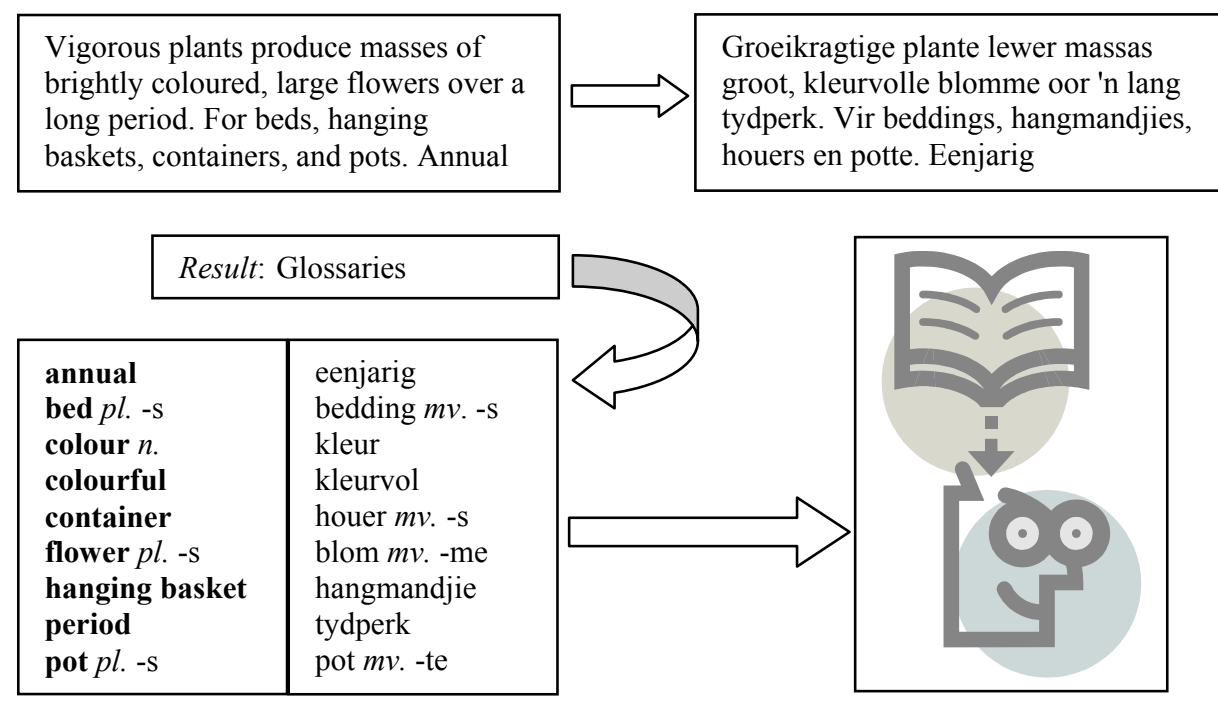

Diagram 2: Translation-oriented terminography

\subsection{Linguistic community-oriented terminography}

Terminology is also harvested from rural and urban speech communities (community-oriented terminography) for documentation in the central terminology bank. This process which entails field-work is costly and therefore seldom undertaken. The fact that terms existing in the communities are not documented contributes to the general stereotype that the African languages are incapable of naming abstract concepts. This is a fallacy. Various terms in a variety of domains already exist in the African languages. The problem is that these terms are not documented and therefore not standardised. The various dialects also contain a wealth of terms which could be harvested and utilised in the standard languages.

For terminology development in a specific language to be effective, trained terminologists should be in a position to do field-work to obtain and document the terminology that exists in various subject areas and domains in the relevant language. Since the terms are not documented in a systematic format (e.g. database), they cannot be standardised. More than one term for the same concept exist in the same language, leading to duplication, confusion and poor communication. The language-specific terminologist should visit rural areas to document the terminology related to animal names, bird names, customs and beliefs, traditional medicines, etc. (i.e. linguistic community-orientated terminography). These terms could be obtained from the older members 
of the linguistic community. Should these people die, the knowledge of terms and related information (i.e. indigenous knowledge systems) dies with them.

The language-specific terminologist should also do field-work in the urban areas - especially at language offices and tertiary institutions where the terminologist could excerpt terms and related information from translated documents, textbooks, curricula, master's dissertations and doctoral theses at various departments (e.g. Physics, Zoology, Chemistry, Psychology, Sociology, Art, etc). These terms are new, and if they are not documented (and translated into the relevant official languages where needed), they could not be standardised and disseminated to target users. It is only by documenting terms and related information, standardising terms and disseminating term lists in various domains and subject areas that the South African indigenous languages will become functional languages in all spheres of life.

This argument also underpins the principle of translation-oriented terminography where translators harvest the source language terms and their target language equivalents when translating. The National Language Service (NLS) established pilot Language Research and Development Centres (LRDCs) in geolinguistic areas and, while in existence, these Centres also functioned as depositories of harvested terminology which was then submitted to the Terminology Coordination Section (TCS).

Should PanSALB employ trained terminologists at the various National Lexicography Units (NLUs), these terminologists will be situated at tertiary institutions where they could harvest terminology as described above. They are already situated in the geolinguistic area where the most first-language speakers reside and would be in a position to do field-work as suggested. They will also be able to contribute multilingual polythematic terms to the envisaged Human Language Technologies (HLT) virtual network (see section 9).

PanSALB and the National Language Bodies (NLBs) would be in a better position to assist with terminology development in the country. Terminology endeavours by various language-specific compilers of technical dictionaries could be coordinated. The terminology of a specific language could be verified by the relevant NLBs the moment the term list is compiled. The specific language could publish the terminological information immediately after the verification and authentication process and after applicable changes were made to the database. The terminology list could be disseminated to target users such as language practitioners, journalists, etc. without having to wait for the other languages to be completed (such is the case for national projects). All these terms and related information should be submitted to the national term bank at the NLS.

\section{Terminology models in Africa to be implemented by South Africa}

South Africa is the only country in Africa where terminology is officially practised separately from lexicography. The South African model functions well in 
cases where national terminology projects need to be undertaken (e.g. school terminology lists for the national Department of Education). Unfortunately this model does not work for the general terminology development of a specific language.

The models of respectively the Institute for Kiswahili Research at the University of Dar es Salaam, Tanzania and the African Languages Research Institute (ALRI), University of Zimbabwe, Harare, Zimbabwe could serve as examples where both lexicography and terminography work are done at the same institution.

In the case of the Institute for Kiswahili Research, the lexicographers work on a variety of general dictionaries, e.g. monolingual Swahili dictionaries (explanatory dictionaries; school or learner's dictionaries, etc.) or various types of bilingual dictionaries (Swahili-English). It also houses terminologists who compile monolingual or bilingual technical dictionaries in various subject fields, e.g. Physics, Chemistry, Biology, etc.).

In the case of ALRI, the lexicographers compile monolingual, bilingual and multilingual dictionaries. Monolingual general dictionaries for Shona and Ndebele have already been published (e.g. Duramazwi reChiShona (1996), Isichazamazwi SesiNdebele (2001); Duramazwi Guru reChiShona (2001), etc.). These dictionaries are only some of several subprojects undertaken by the African Languages Lexical (ALLEX) Project at the University of Zimbabwe. At the same time, the terminologists at ALRI have compiled a number of technical dictionaries in Shona and Ndebele (sometimes in combination with English), e.g. Duramazwi reUrapi neUtano (2004), Duramazwi reMimhanzi (2005), Isichazamazwi SezoMculo (2006), Duramazwi reDudziramutauro neUvaranomwe (2007), etc.

In South Africa, official terminology work could still continue on a national basis by the Terminology Coordination Section (TCS) as described in section 6. Language-specific terminologists could assist with the documentation of terminology that at present exists in the various indigenous languages (e.g. created by translators, interpreters, journalists, the community radio, the media, and the linguistic community at large.

Computerised versions of the terminology documented by language-specific terminologists could be sent to the national terminology office, TCS, for inclusion in the national term bank managed by the NLS. This work could be done online since all National Lexicography Units (NLUs) and other terminology compilers work on TshwaneLex and TshwaneTerm (locally developed custom-made software) which are compatible with MultiTerm and TRADOS.

The terminological inputs to the national term bank by collaborators such as translators working in various government departments, national parliament, the erstwhile Language Research and Development Centres (LRDCs), PanSALB structures such as the NLUs and National Language Bodies (NLBs), and private terminology initiatives could solve the problem of term documentation and dissemination. Present problems experienced in South Africa regarding the process of standardisation and communication could be solved. 


\section{Terminology training}

The Terminology Coordination Section (TCS) of the National Language Service (NLS), Department of Arts and Culture (DAC) provides in-house training as official national terminology office. Unfortunately there is only one terminologist per language at TCS. These terminologists are not enough to solve the subject-related communication problems since they cannot cope with the demand to supply multilingual terminology in the diversity of subjects or domains that need multilingual terminology. Various national and provincial departments and local authorities created language units to assist with language-related work such as translation, editing, interpreting and terminology harvesting.

There are at present only a few tertiary institutions in South Africa that offer official courses in terminology theory and principles. Aspects relating to these are dealt with in courses in translation or lexicography studies. Terminology training as such receives too little attention in these courses to be worthwhile. South African tertiary institutions will have to offer terminology training to people interested in this profession to solve the subject-related communication problems.

Since several language offices employ language practitioners such as translators, editors and interpreters, there is an urgent need for basic training in terminological principles and practice. They are creating new terms on a daily basis and need to acquire skills on word-forming principles, terminology management and standardisation (to name a few). At present the author of this article is providing terminology training on principles and practice of terminology and terminography to interested individuals, language bodies and language-related institutions. The multilingual dispensation requires skilled language workers, and the terminology training is aimed at enabling language workers to manage terminology in all aspects thereof.

\section{The Human Language Technologies (HLT) initiative}

The South African Government has approved the development of a human language technologies (HLT) virtual network. All lexicographical and terminographical endeavours will be part of the HLT virtual network. Multilingual terms will for instance be available on the HLT virtual network to end-users such as subject specialists, students, language practitioners and the general public.

\section{Conclusion}

The language policy of a country influences terminology development since it determines which languages to be developed. Terminology development 
should adhere to the language policy and to sound terminological and terminographical principles and procedures.

Specialised communication has a central axle or hub in terminology. Terminology is therefore a strategic resource and has an important role in a country's development - especially in a multilingual country.

Effective economic, scientific and technical communication skills of the citizens of a country are developed through the use of correct and standardised terminology. The terminology practice of any country will enhance communication in various domains and will develop official (and national) languages into functional languages.

\section{Literature}

Budin, G. 2004. Draft Report: National Language Services. 15 May 2004. Unpublished report. Pretoria: NLS, DAC.

Chin, Jeff. 2009. http://google-africa.blogspot.com/2009/09/google-translate-now-available-for. html

Cluver, A.D. de V. 1996. Language Development. Proceedings of a LANGTAG Workshop on Issues in Language Development: Focusing on the Future of the Apartheid Language Boards and the Harmonisation and Development of African Languages. 28 March 1996, Unisa, Pretoria. State Language Services. DACST.

Constitution of the Republic of South Africa. 1996. (Act 108 of 1996). Pretoria: Government Printer.

Department of Arts, Culture, Science and Technology. 1996. Proceedings of a LANGTAG Workshop on Issues in Language Development. Focusing on The Future of the Apartheid Language Boards and The Harmonisation and Development of African Languages. 28 March 1996. Pretoria: State Language Services, DACST.

Department of Arts, Culture, Science and Technology. 1996. Towards a National Language Plan for South Africa. The final LANGTAG Report. Pretoria: DACST.

English National Language Body, PanSALB. 2007. English and Multilingualism in South African Society: Papers from the English National Language Body. Unpublished document. Pretoria: PanSALB.

Haugen, E. 1966. Dialect, Language, Nation. American Anthropologist 68: 922-935.

http://en.wikipedia.org/wiki/Languages_fo_Africa

Mayevu, G.S. 1996. Development of the South African Literatures with Special Reference to Xitsonga. Department of Arts, Culture, Science and Technology. 1996. Proceedings of a LANGTAG Workshop on Issues in Language Development. Focusing on The Future of the Apartheid Language Boards and The Harmonisation and Development of African Languages. 28 March 1996. Pretoria: State Language Services, DACST.

Mojela, M.V. 2007. Translators: Conveying the Message. Paper read at the International Translation Day celebration 2007: Don't Shoot the Messenger! George Bou Conference Centre, 29-30 October 2007, Pretoria.

Mtintsilana, P.N. and R. Morris. 1988. Terminography in African Languages in South Africa. South African Journal of African Languages 8(4): 109-113. 
National Language Policy Framework (NLPF) and Implementation Plan. 2003. Pretoria: DAC.

Ntshangase, D. 1996. Working Document: Future of the Present Language Boards. LANGTAG Subcommittee on the Development of (South) African Languages, 20 February 1996. Unpublished document. Pretoria: DAC.

PanSALB. 2001a. Language Use and Language Interaction in South Africa. A National Sociolinguistic Survey. Pretoria: PanSALB.

PanSALB. 2001b. Guidelines for Language Planning and Policy Development. Pretoria: PanSALB.

Pan South African Language Board Act. 1995. (Act No 59 of 1995). Pretoria: Government Printer.

Random House. 1987. Random House Dictionary of the English Language. Second Edition. New York: Random House.

Unit for Language Management. 2007a. SA Language Rights Bulletin 2(1), September 2007. Prepared for the Pan South African Language Board by the Unit for Language Management, University of the Free State.

Unit for Language Management. 2007b. SA Language Rights Bulletin 2(2), September 2007. Prepared for the Pan South African Language Board by the Unit for Language Management, University of the Free State.

Webb, V. n.d. The Role of Language in Economic Development. Unpublished document.

Wright, Laurence. 2007. Language Policy and Planning: General Constraints and Pressure. English National Language Body, PanSALB. 2007. English and Multilingualism in South African Society: Papers from the English National Language Body: 6-11. Unpublished document. Pretoria: PanSALB. 